\title{
Vitamin D receptor genetic variants are associated with susceptibility of gallbladder adenocarcinoma in a Chinese cohort
}

\author{
Z. Li, W.T. Yuan, S.J. Ning and S.J. Zhang \\ Department of General Surgery, \\ The First Affiliated Hospital of Zhengzhou University, \\ Zhengzhou, Henan, China \\ Corresponding author: S.J. Zhang \\ E-mail: drzhenli@aliyun.com
}

Genet. Mol. Res. 13 (3): 5387-5394 (2014)

Received June 3, 2013

Accepted November 18, 2013

Published July 24, 2014

DOI http://dx.doi.org/10.4238/2014.July.24.18

\begin{abstract}
The aim of this study was to test for the possible association between vitamin $\mathrm{D}$ receptor (VDR) genetic variants and susceptibility to gallbladder cancer (GBC). A total of 291 GBC cases were recruited and 396 gender- and age-matched healthy volunteers were enrolled as controls. The $V D R$ gene polymorphisms were determined in all subjects. The genotype and the allele frequencies of ApaI, Bsm I, and TaqI polymorphisms were not significantly different between GBC subjects and controls. However, the genotype and allele frequencies of the FokI C>T polymorphism were significantly different between GBC subjects and controls. The FokI TT genotype was in markedly higher frequency in GBC subjects compared to controls (38.14 vs $22.73 \%$, $\mathrm{P}<0.001)$. Using TT as the reference genotype, multivariate logistic regression analysis showed that $\mathrm{CC}$ genotype carriers had a higher risk of $\mathrm{GBC}$ (adjusted odds ratio $(\mathrm{OR})=3.423$, adjusted $\mathrm{P}=0.001$ ) with adjustment for age, gender, smoking status, alcohol use, and gallstone presence, as well as the serum 1,25(OH)2D level. Carriers of the CT genotype also had a higher risk of GBC (adjusted OR $=1.992$, adjusted
\end{abstract}


$\mathrm{P}=0.003$ ). Multivariate logistic regression analysis did not reveal any association between the ApaI, BsmI, and TaqI polymorphisms and GBC risk (all $\mathrm{P}>0.05)$.

Key words: Vitamin D receptor; Gallbladder cancer; Susceptibility

\section{INTRODUCTION}

Gallbladder cancer (GBC) is one of the most common malignant neoplasms of the digestive tract (Erickson and Nag, 1998). GBC has a multifactorial etiology including gender, obesity, chronic cholecystitis, gallstones, and occupational exposure to specific chemicals (Moerman et al., 1997; Lowenfels et al., 1999; Pandey and Shukla, 2002; Serra et al., 2002). Previous studies have shown that genetic factors are also involved in the development of GBC in several populations (Zatonski et al., 1997; Roa et al., 2000; Pitt and Brenner, 2003; Qiu et al., 2005; Kim et al., 2008). Several genetic polymorphisms have been reported as potential molecular markers for GBC (Srivastava et al., 2008a,b, 2010). However, ideal candidate gene prediction of GBC risk is still under investigation.

Epidemiological studies indicate that vitamin D insufficiency could play an etiological role in various human cancers (Peterlik et al., 2009; Garland et al., 2009; Trump et al., 2009; Hines et al., 2010; Mitchell, 2011). The effect of vitamin D is mediated by the vitamin D receptor (VDR), a member of the nuclear receptor superfamily of ligand-inducible transcription factors, which are involved in many pathological processes (Subramaniam et al., 2001; Kato and Yoko, 2004; Slattery, 2007). Several singlenucleotide restriction fragment length polymorphisms (RFLPs) have been described in the $V D R$ gene in association with carcinogenesis. Increasing studies have revealed that VDR gene polymorphisms influence the risk of certain cancers, including breast, prostate, skin, colon-rectum, bladder, and liver cancer, as well as renal cell carcinoma and malignant melanoma (Slattery et al., 2001, 2007; Han et al., 2007; Yaylim-Eraltan et al., 2007; Li et al., 2008; Kostner et al., 2009). However, the role of VDR gene polymorphisms in determining the risk for $\mathrm{GBC}$ remains undocumented. In the present study, we performed a case-control analysis in Chinese cohorts to test the possible association between VDR genetic variants and GBC.

\section{MATERIAL AND METHODS}

\section{Study subjects}

We enrolled 291 patients with histologically confirmed gallbladder adenocarcinoma from March 2003 to December 2010 at our hospital. The exclusion criteria were as follows: occupational exposure to ultraviolet radiation or chemical carcinogens, chronic bacterial infections, typhoid carrier, and ulcerative colitis. A further 396 gender- and agematched healthy volunteers were enrolled as controls. Informed consent, blood samples, and clinical evaluations were collected from all subjects according to protocols that were approved by the Institution Review Boards of the Ethics Committees of all of the participating institutes. 


\section{Sample collection and genotyping}

Ten milliliters of venous blood was collected from each patient into tubes containing $50 \mathrm{mM}$ ethylenediaminetetraacetic acid (EDTA), and genomic DNA was isolated with the DNA Blood Mini kit, according to manufacturer instructions (QIAGEN, Shanghai, China). Four diallelic polymorphisms of VDR were genotyped: The FokI C $>\mathrm{T}(\mathrm{rs} 10735810)$ and Taq $\mathrm{I}$ $\mathrm{T}>\mathrm{C}$ (rs10735810) polymorphic sites on the coding sequence, and the BsmI A $>\mathrm{G}$ (rs1544410) and ApaI G>T (rs7975232) polymorphisms on the last intron. The polymerase chain reaction (PCR) technique was applied followed by RFLP assays. The primers and conditions for the $V D R$ polymorphisms are listed in Table 1. All PCR products were identified by electrophoresis on $2 \%$ agarose gel stained with ethidium bromide.

\begin{tabular}{|c|c|c|c|}
\hline SNP & Primer & Base change & $\mathrm{T}\left({ }^{\circ} \mathrm{C}\right)$ \\
\hline FokI & $\begin{array}{l}\text { F: 5'-AGCTGGCCCTGGCACTGACTCTGCTCT-3' } \\
\text { R: 5'-ATGGAAACACCTTGCTTCTTCTCCCTC-3' }\end{array}$ & $\mathrm{C} / \mathrm{T}$ & 61 \\
\hline Bsm I & $\begin{array}{l}\text { F: 5'-CAACCAAGACTACAAGTACCGCGTCAGTGA-3' } \\
\text { R: 5'-AACCAGCGGGAAGAGGTCAAGGG-3' }\end{array}$ & $\mathrm{G} / \mathrm{A}$ & 57 \\
\hline ApaI & $\begin{array}{l}\text { F: 5'-CAGAGCATGGACAGGGAGCAA-3' } \\
\text { R: 5'-GCAACTCCTCATGGCTGAGGTCTC-3' }\end{array}$ & $\mathrm{G} / \mathrm{T}$ & 60 \\
\hline TaqI & $\begin{array}{l}\text { F: 5'-CAGAGCATGGACAGGGAGCAA-3' } \\
\text { R: 5'-GCAACTCCTCATGGCTGAGGTCTC-3' }\end{array}$ & $\mathrm{T} / \mathrm{C}$ & 60 \\
\hline
\end{tabular}

\section{Serum levels of $1,25(\mathrm{OH}) 2 \mathrm{D}$}

The serum levels of 1,25(OH)2D were measured in a 25(OH)2D3-Elecsys vitamin D3 chemiluminescent immunoassay system (Roche Diagnostics, Mannheim, Germany) by using a photomultiplier (Elecsys 2010; Hitachi, Tokyo, Japan).

\section{Statistical analyses}

The $\chi^{2}$ test was used to compare genotype frequencies and demographic distributions between cases and controls. Multiple logistic regression analysis was used to evaluate whether each polymorphism was independently associated with GBC when adjusted for the potential confounding effects of important clinical variables. The odds ratios (ORs) and 95\% confidence intervals (CIs) were calculated. The associations between $V D R$ haplotypes and GBC risk were analyzed. Linkage disequilibrium (D' value) of the 4 single-nucleotide polymorphisms (SNPs) studied was calculated with the SHEsis software (Shi and He, 2005). The differences in overall survival (OS) and progression-free survival (PFS) across different genotypes were compared using the log-rank test with adjustments for age, gender, smoking status, cancer stage, differentiation status, and chemotherapy regimens. A Cox regression model was performed to obtain the adjusted hazard ratio (HR) and $95 \% \mathrm{CI}$ of potential prognostic factors for OS in GBC patients. P $<0.05$ was considered to be statistically significant. All analyses were conducted with the Statistical Package for the Social Sciences (SPSS version 16.0; SPSS Inc., Chicago, IL, USA). 


\section{RESULTS}

The clinical characteristics of GBC cases and controls are listed in Table 2. There were more smokers, alcohol users, and gallstones in the GBC group than in the control group $(\mathrm{P}<0.05)$. The GBC group had a significantly lower mean serum 1,25(OH)2D level compared to controls $(\mathrm{P}<0.001)$.

Table 2. Clinical characteristics of gallbladder cancer (GBC) cases and controls.

\begin{tabular}{lccr}
\hline Characteristic & Controls & GBC & P \\
\hline Gender (female, \%) & 66.62 & 67.96 & 0.452 \\
Age (years) & $51.73 \pm 6.24$ & $51.41 \pm 8.18$ & 0.569 \\
BMI $\left(\mathrm{kg} / \mathrm{m}^{2}\right)$ & $22.8 \pm 2.3$ & $22.1 \pm 1.4$ & 0.053 \\
Tobacco users (\%) & 20.7 & 36.60 & 0.011 \\
Alcohol users $(\%)$ & 18.45 & 25.58 & 0.004 \\
Gallstone presence $(\%)$ & 9.63 & 36.67 & $<0.001$ \\
Serum $1,25(\mathrm{OH}) 2 \mathrm{D}(\mathrm{ng} / \mathrm{mL})$ & $34.3 \pm 4.6$ & $22.4 \pm 6.7$ & $<0.001$ \\
\hline
\end{tabular}

Data are reported as means $\pm \mathrm{SD}$, unless otherwise explained.

The genotype frequencies of VDR polymorphisms in GBC subjects and controls were found to be in Hardy-Weinberg equilibrium (all $\mathrm{P}>0.05$ ). The genotype and allele frequencies of ApaI, FokI, BsmI, and TaqI in cases and controls are shown in Table 3. The genotype and allele frequencies of $A p a \mathrm{I}, F o k \mathrm{I}, B s m \mathrm{I}$, and TaqI were not significantly different between GBC and controls. However, the genotypes and allele frequencies of the FokI $\mathrm{C}>\mathrm{T}$ polymorphism were significantly different between GBC subjects and controls. GBC subjects had a markedly higher FokI TT genotype frequency compared to controls $(38.14$ vs $22.73 \%, \mathrm{P}<0.001)$. Using the TT genotype as reference, multivariate logistic regression analysis showed that CC genotype carriers had a higher risk of developing GBC (adjusted $\mathrm{OR}=3.423$, adjusted $\mathrm{P}=$ 0.001 ) with adjustment for age, gender, smoking status, alcohol use, and gallstone presence as well as the serum 1,25(OH)2D level. The CT genotype also represented a higher risk for GBC (adjusted $\mathrm{OR}=1.992$, adjusted $\mathrm{P}=0.003$ ). However, multivariate logistic regression analysis did not reveal any association between the $A p a \mathrm{I}, B s m \mathrm{I}$, and TaqI polymorphisms and GBC risk (all P > 0.05; Table 3).

\section{$V D R$ haplotypes and GBC risk}

The associations between the $V D R$ haplotypes and the GBC risk were analyzed in this study. The D' values of the 4 SNPs analyzed were calculated with the SHEsis software. All 4 SNPs were in strong linkage disequilibrium (all D'>0.8). The estimated haplotype frequencies of the VDR SNPs are shown in Table 4. The haplotypes $\mathrm{C}_{F o k}-\mathrm{A}_{B s m}-\mathrm{G}_{A p a}-\mathrm{T}_{T a q}, \mathrm{C}_{F o k}-\mathrm{G}_{B s m}-$ $\mathrm{T}_{A p a}-\mathrm{T}_{T a q}$, and $\mathrm{C}_{F o k}-\mathrm{G}_{B s m}-\mathrm{T}_{A p a}-\mathrm{C}_{T a q}$ showed a significantly higher risk of developing $\mathrm{GBC}(\mathrm{OR}=$ $4.967,2.463$, and 1.886, respectively, all $\mathrm{P}<0.05$; Table 4).

We further analyzed the variation of serum 1,25(OH)2D levels in GBC according to $V D R$ genotype distributions. FokI CC genotype carriers had significantly lower 1,25(OH)2D levels (CC: $17.5 \pm 3.2$ vs TC: $23.2 \pm 1.7$ and TT: $23.5 \pm 2.4$, both $\mathrm{P}<0.05$; Figure 1 ). When stratified by the ApaI, BsmI, and TaqI polymorphisms, there were no differences among genotype carriers (data not shown). 
Table 3. Genotype and allele frequencies of $A p a \mathrm{I}, F o k \mathrm{I}, B s m \mathrm{I}$, and TaqI between gallbladder cancer (GBC) cases and controls.

\begin{tabular}{|c|c|c|c|c|c|c|c|c|}
\hline & & GBC & $\mathrm{N}=291$ & Control & $\mathrm{N}=396$ & Adjusted OR & $95 \% \mathrm{CI}$ & Adjusted P value \\
\hline & & $\mathrm{N}$ & $\%$ & $\mathrm{~N}$ & $\%$ & & & \\
\hline \multirow[t]{5}{*}{$\overline{A p a \mathrm{I}}$} & TT & 83 & 28.52 & 104 & 26.26 & 1.000 & & \\
\hline & TG & 125 & 42.96 & 197 & 49.75 & 0.795 & $0.552-1.146$ & 0.218 \\
\hline & GG & 83 & 28.52 & 95 & 23.99 & 1.095 & $0.725-1.653$ & 0.667 \\
\hline & $\mathrm{T}$ & 291 & 50.00 & 405 & 51.14 & 1.000 & & \\
\hline & $\mathrm{G}$ & 291 & 50.00 & 387 & 48.86 & 1.047 & $0.845-1.296$ & 0.677 \\
\hline \multirow[t]{5}{*}{ Bsm I } & AA & 72 & 24.74 & 108 & 27.27 & 1.000 & & \\
\hline & $\mathrm{AG}$ & 176 & 60.48 & 210 & 53.03 & 1.257 & $0.878-1.801$ & 0.211 \\
\hline & GG & 43 & 14.78 & 78 & 19.70 & 0.827 & $0.513-1.332$ & 0.051 \\
\hline & A & 320 & 54.98 & 426 & 53.79 & 1.000 & & \\
\hline & $\mathrm{G}$ & 262 & 45.02 & 366 & 46.21 & 0.953 & $0.769-1.181$ & 0.660 \\
\hline \multirow[t]{5}{*}{ FokI } & TT & 40 & 13.75 & 111 & 28.03 & 1.000 & & \\
\hline & $\mathrm{CT}$ & 140 & 48.11 & 195 & 49.24 & 1.992 & $1.307-3.037$ & 0.003 \\
\hline & $\mathrm{CC}$ & 111 & 38.14 & 90 & 22.73 & 3.423 & $2.169-5.400$ & 0.001 \\
\hline & $\mathrm{T}$ & 220 & 37.80 & 417 & 52.65 & 1.000 & & \\
\hline & $\mathrm{C}$ & 362 & 62.20 & 375 & 47.35 & 1.830 & $1.471-2.275$ & 0.000 \\
\hline \multirow[t]{5}{*}{$\operatorname{Taq} \mathrm{I}$} & TT & 90 & 30.93 & 112 & 28.28 & 1.000 & & \\
\hline & $\mathrm{TC}$ & 156 & 53.61 & 198 & 50.00 & 0.980 & $0.692-1.388$ & 0.912 \\
\hline & $\mathrm{CC}$ & 45 & 15.46 & 86 & 21.72 & 0.651 & $0.413-1.026$ & 0.054 \\
\hline & $\mathrm{T}$ & 336 & 57.73 & 422 & 53.28 & 1.000 & & \\
\hline & $\mathrm{C}$ & 246 & 42.27 & 370 & 46.72 & 0.835 & $0.673-1.036$ & 0.101 \\
\hline
\end{tabular}

\section{Table 4. Haplotype analysis of the VDR gene and gallbladder cancer (GBC) status}

\begin{tabular}{lccccccc}
\hline FokI & BsmI & ApaI & TaqI & GBC (N) & Controls (N) & P & Odds ratio (95\%CI) \\
\hline C & A & G & T & 97 & 15 & $<0.001$ & $4.967(2.873-8.586)$ \\
C & G & T & C & 84 & 31 & $<0.001$ & $2.463(1.807-3.698)$ \\
C & G & T & T & 73 & 75 & 0.034 & $1.866(1.496-2.9737)$ \\
\hline
\end{tabular}

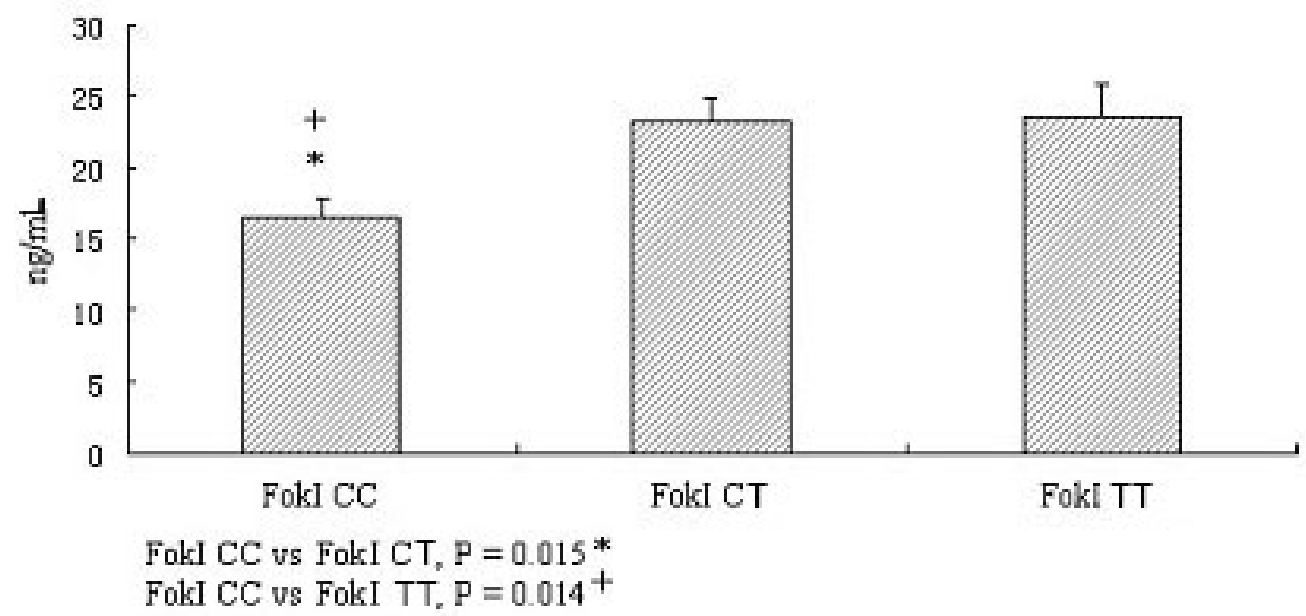

Figure 1. Serum 1,25(OH)2D in gallbladder cancer according to FokI genotype distributions. 


\section{DISCUSSION}

In the present hospital-based study, we investigated the possible association between polymorphisms of the VDR gene and GBC risk. We observed that carriers of the FokI CC and TC genotypes had markedly increased ORs for GBC, suggesting that the $\mathrm{C}$ allele is a risk factor to GBC incidence. The FokI C>T polymorphism also affected the serum 1,25(OH)2D levels. The polymorphisms of the other three loci, ApaI, BsmI, and TaqI, did not show an association with GBC. To our knowledge, our study is the first to report the interaction between $V D R$ polymorphisms and the risk of GBC.

The FokI RFLP, located in the coding region of the VDR gene, results in the production of a VDR protein that is three amino acids longer than the wild-type. Although no significant differences in ligand affinity, DNA binding, or transactivation activity have been found between these two VDR forms when studied independently (Laaksonen et al., 2004), in transient transfection assays with a vitamin D-responsive reporter gene, the shorter VDR variant displayed higher potency than the longer one (Gross et al., 1998). It has been hypothesized that a less active VDR could be associated with either an increased susceptibility to cancer risk or to a more aggressive form of the disease (Kanan et al., 2000). In this study, we found that the FokI polymorphisms of the $V D R$ gene were closely associated with GBC risk, suggesting that this locus could be used as a molecular marker for GBC.

Both in vitro and in vivo studies have shown proapoptotic and anticancer effects upon binding of 1,25-dihydroxyvitamin D to the VDR in many different types of cancers (Reichel et al., 1989). Berger et al. (1988) demonstrated a dose-dependent decrease in the growth rate of melanoma cells treated with $1,25(\mathrm{OH}) 2 \mathrm{D}$. The growth-inhibitory property of $1,25(\mathrm{OH}) 2 \mathrm{D}$ has since been reported in tumor-derived cells from other tissues, including the colon (Platz et al., 2000), breast (Mawer et al., 1997), and prostate (Platz et al., 2004; Tseng et al., 2009). In this study, we found that the 1,25(OH)2D levels were significantly different among different FokI genotype carriers, suggesting that the effect of FokI polymorphisms of the VDR gene on GBC risk might be mediated through the influence on 1,25(OH)2D levels.

Some limitations of this study need to be addressed. First, because this was a hospitalbased study, there is the possibility of enrollment bias. Second, we only enrolled GBC patients in a Chinese cohort; therefore, whether the positive roles of $V D R$ polymorphisms we found in this study also hold in other ethnic populations remains unknown. Third, we did not perform functional analyses to further determine the mechanism under which $V D R$ polymorphisms affect the susceptibility of GBC.

\section{ACKNOWLEDGMENTS}

We thank Dr. Xuwei Hou at University of Mississippi Medical Center for his help in statistic analyses and English revision.

\section{REFERENCES}

\footnotetext{
Berger U, Wilson P, McClelland RA, Colston K, et al. (1988). Immunocytochemical detection of 1,25-dihydroxyvitamin D receptors in normal human tissues. J. Clin. Endocrinol. Metab. 67: 607-613.

Erickson BA and Nag S (1998). Biliary tree malignancies. J. Surg. Oncol. 67: 203-210.

Garland CF, Gorham ED, Mohr SB and Garland FC (2009). Vitamin D for cancer prevention: global perspective. Ann. Epidemiol. 19: 468-483.
} 
Gross C, Krishnan AV, Malloy PJ, Eccleshall TR, et al. (1998). The vitamin D receptor gene start codon polymorphism: a functional analysis of FokI variants. J. Bone Miner. Res. 13: 1691-1699.

Han J, Colditz GA and Hunter DJ (2007). Polymorphisms in the MTHFR and VDR genes and skin cancer risk. Carcinogenesis 28: 390-397.

Hines SL, Jorn HK, Thompson KM and Larson JM (2010). Breast cancer survivors and vitamin D: a review. Nutrition 26: $255-262$.

Kanan RM, Varanasi SS, Francis RM, Parker L, et al. (2000). Vitamin D receptor gene start codon polymorphism (FokI) and bone mineral density in healthy male subjects. Clin. Endocrinol. 53: 93-98.

Kato S and Yoko Y (2004). VDR function in skin. Clin. Calcium 14: 116-119.

Kim JH, Kim HN, Lee KT, Lee JK, et al. (2008). Gene expression profiles in gallbladder cancer: the close genetic similarity seen for early and advanced gallbladder cancers may explain the poor prognosis. Tumour Biol. 29: 41-49.

Kostner K, Denzer N, Muller CS, Klein R, et al. (2009). The relevance of vitamin D receptor (VDR) gene polymorphisms for cancer: a review of the literature. Anticancer Res. 29: 3511-3536.

Laaksonen MM, Karkkainen MU, Outila TA, Rita HJ, et al. (2004). Vitamin D receptor gene start codon polymorphism (FokI) is associated with forearm bone mineral density and calcaneal ultrasound in Finnish adolescent boys but not in girls. J. Bone Miner. Metab. 22: 479-485.

Li C, Liu Z, Wang LE, Gershenwald JE, et al. (2008). Haplotype and genotypes of the VDR gene and cutaneous melanoma risk in non-Hispanic whites in Texas: a case-control study. Int. J. Cancer 122: 2077-2084.

Lowenfels AB, Maisonneuve P, Boyle P and Zatonski WA (1999). Epidemiology of gallbladder cancer. Hepatogastroenterology 46: 1529-1532.

Mawer EB, Walls J, Howell A, Davies M, et al. (1997). Serum 1,25-dihydroxyvitamin D may be related inversely to disease activity in breast cancer patients with bone metastases. J. Clin. Endocrinol. Metab. 82: 118-122.

Mitchell D (2011). The relationship between vitamin D and cancer. Clin. J. Oncol. Nurs. 15: 557-560.

Moerman CJ, Bueno de Mesquita HB, Smeets FW and Runia S (1997). Lifestyle factors including diet and cancer of the gallbladder and bile duct: a population-based case-control study in The Netherlands. Eur. J. Cancer Prev. 6: 139-142.

Pandey M and Shukla VK (2002). Diet and gallbladder cancer: a case-control study. Eur. J. Cancer Prev. 11: 365-368.

Peterlik M, Grant WB and Cross HS (2009). Calcium, vitamin D and cancer. Anticancer Res. 29: 3687-3698.

Pitt HA and Brenner BM (2003). Gallbladder cancer gene hypermethylation: genetics or environment? Ann. Surg. Oncol. 10: $832-833$

Platz EA, Hankinson SE, Hollis BW, Colditz GA, et al. (2000). Plasma 1,25-dihydroxy- and 25-hydroxyvitamin D and adenomatous polyps of the distal colorectum. Cancer Epidemiol. Biomarkers Prev. 9: 1059-1065.

Platz EA, Leitzmann MF, Hollis BW, Willett WC, et al. (2004). Plasma 1,25-dihydroxy- and 25-hydroxyvitamin D and subsequent risk of prostate cancer. Cancer Causes Control 15: 255-265.

Qiu D, Kurosawa M, Lin Y, Inaba Y, et al. (2005). Overview of the epidemiology of pancreatic cancer focusing on the JACC Study. J. Epidemiol. 15 (Supp1 2): S157-S167.

Reichel H, Koeffler HP and Norman AW (1989). The role of the vitamin D endocrine system in health and disease. $N$. Engl. J. Med. 320: 980-991.

Roa I, Melo A, Roa J, Araya J, et al. (2000). P53 gene mutation in gallbladder cancer. Rev. Med. Chil. 128: 251-258.

Serra I, Yamamoto M, Calvo A, Cavada G, et al. (2002). Association of chili pepper consumption, low socioeconomic status and longstanding gallstones with gallbladder cancer in a Chilean population. Int. J. Cancer 102: 407-411.

Shi YY and He L (2005). SHEsis, a powerful software platform for analyses of linkage disequilibrium, haplotype construction, and genetic association at polymorphism loci. Cell Res. 15: 97-98.

Slattery ML (2007). Vitamin D receptor gene (VDR) associations with cancer. Nutr. Rev. 65: S102-S104.

Slattery ML, Yakumo K, Hoffman M and Neuhausen S (2001). Variants of the VDR gene and risk of colon cancer (United States). Cancer Causes Control 12: 359-364.

Slattery ML, Herrick J, Wolff RK, Caan BJ, et al. (2007). CDX2 VDR polymorphism and colorectal cancer. Cancer Epidemiol. Biomarkers Prev. 16: 2752-2755.

Srivastava A, Pandey SN, Choudhuri G and Mittal B (2008a). CCR5 Delta32 polymorphism: associated with gallbladder cancer susceptibility. Scand. J. Immunol. 67: 516-522.

Srivastava A, Pandey SN, Choudhuri G and Mittal B (2008b). Role of genetic variant A-204C of cholesterol 7alphahydroxylase (CYP7A1) in susceptibility to gallbladder cancer. Mol. Genet. Metab. 94: 83-89.

Srivastava A, Choudhuri G and Mittal B (2010). CYP7A1 (-204 A>C; rs3808607 and -469 T>C; rs3824260) promoter polymorphisms and risk of gallbladder cancer in North Indian population. Metabolism 59: 767-773.

Subramaniam N, Leong GM, Cock TA, Flanagan JL, et al. (2001). Cross-talk between 1,25-dihydroxyvitamin D3 and transforming growth factor-beta signaling requires binding of VDR and Smad3 proteins to their cognate DNA recognition elements. J. Biol. Chem. 276: 15741-15746. 
Trump DL, Chadha MK, Sunga AY, Fakih MG, et al. (2009). Vitamin D deficiency and insufficiency among patients with prostate cancer. BJU Int. 104: 909-914.

Tseng M, Giri V, Watkins-Bruner D and Giovannucci E (2009). Dairy intake and 1,25-dihydroxyvitamin D levels in men at high risk for prostate cancer. Cancer Causes Control 20: 1947-1954.

Yaylim-Eraltan I, Arzu EH, Arikan S, Okay E, et al. (2007). Investigation of the VDR gene polymorphisms association with susceptibility to colorectal cancer. Cell Biochem. Funct. 25: 731-737.

Zatonski WA, Lowenfels AB, Boyle P, Maisonneuve P, et al. (1997). Epidemiologic aspects of gallbladder cancer: a case-control study of the SEARCH Program of the International Agency for Research on Cancer. J. Natl. Cancer Inst. 89: 1132-1138. 